\title{
Prevalence of Menstrual Disorders and Menstrual Hygiene among School Going Adolescent Girls in Central Kerala
}

Lucy George* and N. Sabitha

\author{
Research Scholar, Department of Nutrition and Dietetics, Vellalar College for Women, Erode - 638012, \\ Tamil Nadu, India; sabirajan685@gmail.com, anemiamentalhealth2017@gmail.com
}

\begin{abstract}
The present study was carried out in selected schools of Pathanamthitta district, central Kerala to assess the prevalence of menstrual disorders and status of menstrual hygiene among school going adolescent girls. A total of 821 school going adolescent girls (aged 10-19 years) from both urban and rural areas were screened, out of which 670 had onset of menstruation. The data was collected from all 670 eligible participants using a semi-structured questionnaire. The questionnaire included information on age of attaining menstruation (menarche), menstrual hygiene and socio demographic variables. The mean age of onset of menarche was $12.28(\mathrm{SD} \pm 1.03)$ years. Irregular menstrual disorder was observed in $34 \%(n=228)$ of the studied subjects. Problems associated with menstruation observed among the subjects were polymenorrhea, oligomenorrhea, hypomenorrhea and menorrhagia. Among all the studied subjects, 99.7\% (668) were using sanitary pads. As far disposal of pads was concerned, 77.25\% $(n=516)$ disposed their pads by burning, $17.06 \%$ ( $\mathrm{n}=114$ ) flush the used pads in toilets and $1.19 \%(\mathrm{n}=8)$ respondents were throwing the pads outside in open and others were $4.49 \%(n=30)$.
\end{abstract}

Keywords: Adolescent Girls, Menstrual Hygiene, Menstrual Problems, Pathanamthitta District, Central Kerala

\section{Introduction}

Adolescents (10-19 years) constitute about $22.8 \%$ of India's population; approximately one-fifth population of India ${ }^{1}$. Adolescence is a highly formative period for future. Many of the challenges that emerge at this age are rooted in experience in the womb or younger childhood. Effects of neuro-biological changes in very early years can emerge in adolescence and this will influence the behaviors that can lead to many of the life threatening disease and other chronic conditions ${ }^{2}$. Intense physical, psycho-social and cognitive developments are noticed during adolescent's period. During adolescence, there will be increase in their nutritional needs. Consequently, they gain up to $50 \%$ of their weight, more than $20 \%$ of their height, and $50 \%$ of their skeletal structure during this period ${ }^{3}$.

Menstruation is an issue in an adolescent girl's life with medical, social and psychological dimensions. It is a milestone event in female puberty and an important indicator of reproductive health ${ }^{4}$. Menstrual cycle irregularity has a physiological dimension and it is necessary to determine whether diagnostic procedures need to be initiated. Hypothalamus-pituitary-ovary axis immaturity could be one of the reasons for irregular menses ${ }^{5}$.

General health, genetic, socio-economic and nutritional factors influence the age of menarche. The mean age of menarche is typically between 12 and 13 years ${ }^{\underline{6}}$. Hygiene-related practices of women during

${ }^{*}$ Author for correspondence 
menstruation needs attention as it increases vulnerability to Reproductive Tract Infections (RTI). The interaction between socio-economic status, menstrual hygiene practices and RTI is significant. Today millions of women are sufferers of RTI and its complications and often the infection is transmitted to the offspring through pregnancy.

Women having better knowledge regarding menstrual hygiene and related problems right from childhood may adopt safe practices and may help in mitigating their suffering, with the above background, this study was undertaken to assess the prevalence of menstrual disorders among the school going adolescent girls and to find out the status of menstrual hygiene among school going adolescent girls.

\section{Methodology}

\subsection{Study Setting and Study Population}

In order to meet the objectives, the study adopted a cross-sectional design by focusing on schools. The present study was done among the adolescent girls in rural and urban schools of Pathanamthitta district, central Kerala. Eight hundred and twenty-one girls of standard V to XII were screened for the study. Out of this, only 670 respondents had attained menarche and hence they were included in the study.

\subsection{Sample Selection}

A previous study conducted in Kerala reported 21.86\% prevalence of irregularity in menstrual cycle ${ }^{7}$. Based on this available data, the sample size was calculated using the statistical formula given below:

$\left.(\mathrm{Za})^{2} \mathrm{PQ}\right) \div \mathrm{d}^{2}$

Where $\mathrm{Za}$ is $1.96, \mathrm{P}$ is the prevalence of irregularities in menstruation as found from previous study i.e., $21.86 \%$ and $\mathrm{Q}=(100-\mathrm{P})$. The precision for the present study is estimated as $d=20 \%$ of $P$.

The estimated minimum sample size was 352 .

In the present study, 821 school-going adolescent girls of age group 10-19 years from both urban and rural areas were screened initially of whom only 670 had onset of menstruation. The data was collected from all the 670 participants, which is about twice the estimated sample size.

\subsection{Data Collection Tools and Techniques}

After seeking prior permission from the school authorities, concerned teachers of the class V to XII were explained the purpose of the study and rapport was built with the girl students and written consent from the parents and students was obtained. Briefing was done to the students regarding the study and data was collected using a semi structured questionnaire. It included age of attaining menstruation (menarche), menstrual hygiene apart from their socio demographic variables.

The different study variables used are defined as follows. Regular menstruation: Menstrual cycle repeated once in every 28-32 days, with duration 3-7 days. Oligomenorrhoea: menstrual cycle duration more than 32 days. Polymenorrhoea: Menstrual cycle duration less than 21 days. Hypomenorrhoea: duration of menstruation $<3$ days and slight blood loss (using $<1$ pad). Menorrhagia: Duration of menstruation $>7$ days and blood loss $>80 \mathrm{~mL}$ (using $\geq 5$ pads). Premenstrual Menstrual Syndrome (PMS) ${ }^{z}$. At the end, after collection of data from the students, all their queries related to the study were answered by the researcher. A short interactive session on menstrual disorders and hygiene practices was also conducted in each school.

\subsection{Statistical Analysis}

The collected data was entered in Microsoft Excel spread sheet and Statistical Package for Social Sciences (SPSS version 16) software was used to analyze the data. Quantitative variables were summarized as means and standard deviations, qualitative variables were expressed in terms of frequencies and proportions. Chi square test was done to find out association between categorical variables, at significance level of 0.05 .

\section{Results and Discussion}

The focus of the study was to estimate the prevalence of menstrual disorders and menstrual hygiene practices in the rural and urban schools of central Kerala. Menstrual disorders include menstrual cycle irregularities (of duration or length), hypomenorrhoea, polymennrohea, oligomenorrhoea, menorrhagia and Premenstrual Syndrome (PMS).

The mean age of the study participants (670) is $(15.02 \pm 1.52)$ years. The minimum age is 10.20 years and 
maximum age was 15.20 years. About 461 participants (68.8\%) belong to rural schools and 209 (31.2\%) are from urban schools. Out of 670 participants, $54.8 \%$ of respondents were Hindus, $41.2 \%$ were Christians and $4.0 \%$ were muslims.

\subsection{Age at Menarche}

Out the 821girls in the adolescent age group, only $670(81.60 \%)$ have attained menarche and the rest 151 (18.4\%) respondents are not included in the analysis. The mean age of onset of menarche was $12.28(\mathrm{SD} \pm 1.03)$ years with the median at 12 years i.e. $50 \%$ of respondents had attained their menarche at 12 years. The minimum age of attainment of menarche was 9 years and maximum age was 15 years. In similar studies the mean age was $12.8 \pm 1.3$ of 9-17 years $\stackrel{8}{ }$. And another study shows $12.5 \pm 1.52$ for 10-15 years? ${ }^{9}$. The mean age at menarche is found to be strongly linked to the mean female life expectancy and sexual maturation and many other factors influenced the onset of menarche ${ }^{10}$.

As per (Figure 1), it is seen that $143(21.3 \%)$ are in the early adolesent stage while majority of the adolscents fall under middle category i.e. 444 (66.3\%) and only 83 (12.4\%) belong to the late stage.

\subsection{Menstrual Disorders}

The present study shows 34\% prevalence of irregular menstruation. From (Table 2), it is seen that 143 (21.35\%) participants reported irregular cycle in the early adolescents. Out of this, 40 (36\%) were from the rural area and 12 (37.5\%) girls were from the urban area. Out of $444(66.26 \%)$ middle adolescent reported irregular cycle out of which 111 (38\%) were in the rural and 44 (28.9\%) in the urban area. Only $16(27.6 \%)$ and $5(20 \%)$ reported menstrual irregularities from the late adolescent group $83(12.38 \%)$ in the rural and urban respectively. There is no significant difference in the prevalence of menstrual irregularities across the different adolescent categories in both urban and rural areas or collectively as evident from

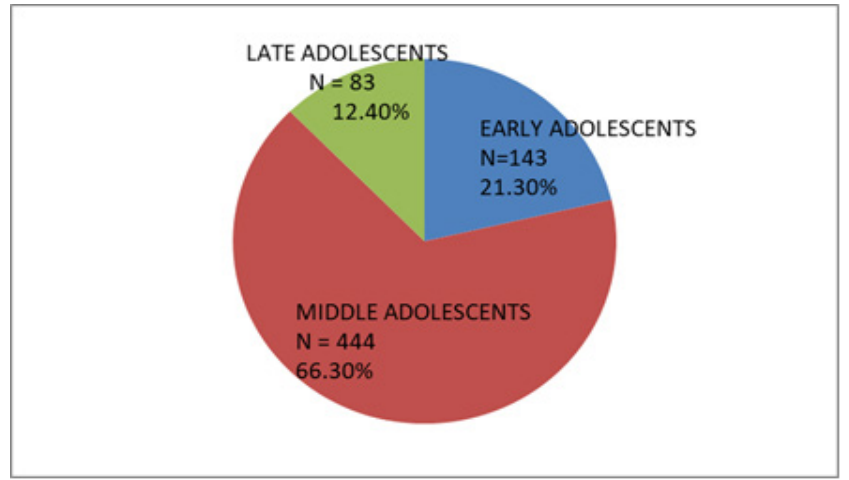

Figure 1. Adolescent age distribution.

the chi-square and $\mathrm{p}$ values in the table. About one third of the girls in all three categories have irregular menstrual cycle $22.8 \%, 67.8 \%$ and $9.21 \%$ respectively. A study by Sinha et al ${ }^{11}$ observed "irregular cycle of $29.4 \%$ (10- 13 years), 14-16 years (11.8\%) and 17-19 years (16.1\%)”. Another study by Sachan ${ }^{12}$ reported "the irregular cycle in adolescents as $22.6 \%$ and $31.8 \%$ respectively".

Table 3, shows other menstrual disorders in the age category of adolescents. A few problems associated with Menstruation are polymenorrhea, oligomenorrhea, hypomenorrhea and menorrhagia. Premenstrual symptoms are quiet common in adolescent stage.

The present study reveals different patterns regarding menstrual disorders, 134 (67\%) in the middle adolescents and $46(23 \%)$ in the early adolescents and late adolescents 20 (10\%) reported Oligomenorrhea. Another study by Bachmann and Kemmann ${ }^{13}$ showed "prevalence of oligomenorrhea in this group is $11.3 \%$ and that of amenorrhea is $2.6 \%$. Weight loss greater than 20 pounds is one of the significant factors associated with oligomenorrhea or amenorrhea". Endocrine dysfunction can cause heavy menstrual bleeding and prolonged menstruation intervals with anovulation ${ }^{14}$.

In the present study, 53 girls in all the three categories reported Polymennorhea which is $14(26.4 \%), 35$ (66\%) and $4(7.5 \%)$ respectively. Another study shows $3.0 \%$ (95\%CI 2.5\%-3.4\%) of the girls had menstruation intervals of less than 21 days ${ }^{15}$. The prevalence of Hypomennorhea

Table1. Age distribution and age at menarche $(n=670)$

\begin{tabular}{|l|c|c|c|}
\hline Adolescent category & Frequency (\%) & \multicolumn{2}{|c|}{ Age at menarche of adolescent girls } \\
\hline Early 10-13 & $143(21.3 \%)$ & Early menarche 10-12 & $392(58.5 \%)$ \\
\hline Middle 14-16 & $444(66.3 \%)$ & Medium menarche 13-14 & $269(40.1 \%)$ \\
\hline Late 17-19 & $83(12.4 \%)$ & Delayed menarche 15-17 & $9(1.3 \%)$ \\
\hline
\end{tabular}


Table 2. Prevalence of irregularities in menstruation among rural and urban adolescent girls $(\mathrm{n}=228)$

\begin{tabular}{|l|c|c|c|}
\hline $\begin{array}{l}\text { Adolescent } \\
\text { Category }\end{array}$ & Rural $(\mathbf{N}=461)$ & Urban $(\mathbf{N}=\mathbf{2 0 9})$ & Total N = 670 \\
\hline $\begin{array}{l}\text { Early adolescents } \\
\text { Rural = 111 } \\
\text { Urban = 32 }\end{array}$ & $40(36 \%)$ & $12(37.5 \%)$ & $52(36.4 \%)$ \\
\hline $\begin{array}{l}\text { Middle adolescents } \\
\text { Rural = 292 } \\
\text { Urban = 152 }\end{array}$ & $111(38 \%)$ & $44(28.9 \%)$ & $155(34.9 \%)$ \\
\hline $\begin{array}{l}\text { Late adolescents } \\
\text { Rural = 58 } \\
\text { Urban =25 }\end{array}$ & $16(27.5 \%)$ & $5(20 \%)$ & $21(25.3 \%)$ \\
\hline & 167 & & \\
\cline { 2 - 4 } & P value-0.320 & & \\
\hline & $2=2.28$ & $\begin{array}{l}\mathrm{P}=0.351 \\
x_{2}=2.09\end{array}$ & $\begin{array}{l}\mathrm{P}=0.190 \\
x_{2}=3.317\end{array}$ \\
\hline
\end{tabular}

Table 3. Distribution of adolescents menstrual disorders category $n=670$

\begin{tabular}{|l|c|c|c|c|c|}
\hline Adolescent category & $\begin{array}{c}\text { Polymenorrhea } \\
\text { (\% within } \\
\text { polymennorrhea } \\
\text { in each category) }\end{array}$ & Hypomenorrhea & Oligomenorrhea & Menorrhagia & $\begin{array}{c}\text { Pre-menstrual } \\
\text { symptoms (PMS) }\end{array}$ \\
\hline Early adolescents143 & $14(26.4 \%)$ & $38(24.5 \%)$ & $46(23 \%)$ & $35(24.6 \%)$ & $88(19.5 \%)$ \\
\hline Middle adolescents444 & $35(66 \%)$ & $98(63.2 \%)$ & $134(67 \%)$ & $94(66.2 \%)$ & $306(67.8 \%)$ \\
\hline Late adolescents-83 & $4(7.5 \%)$ & $19(12.3 \%)$ & $20(10 \%)$ & $13(9.2 \%)$ & $57(12.6 \%)$ \\
\hline $\begin{array}{l}\text { Total -670 } \\
\text { (prevalence) }\end{array}$ & $53(7.91 \%)$ & $155(23.1 \%)$ & $200(29.85 \%)$ & $142(21.19 \%)$ & $451(67.31 \%)$ \\
\hline & $\begin{array}{l}\mathrm{P}=0.410 \\
x 2=1.78\end{array}$ & $\begin{array}{l}\mathrm{P}=0.539 \\
x 2=1.23\end{array}$ & $\begin{array}{l}\mathrm{P}=0.427 \\
x 2=1.702\end{array}$ & $\begin{array}{l}\mathrm{P}=0.295 \\
x 2=2.44\end{array}$ & $\begin{array}{c}\mathrm{P}=0.252 \\
22=2.75\end{array}$ \\
\hline
\end{tabular}

is $155(23.1 \%)$ which is $38(24.5), 98(63.2 \%)$ and 19 $(12.3 \%)$ early, middle and late respectively which is considerably high in the middle adolescents and in the early adolescents.

Menorrhagia is also found to be high among girls in the present study $142(21.19 \%)$ in which $35(24.6 \%)$ in early stage, 94 (66.2\%) are in middle and late adolescents $13(9.2 \%)$. Excessive bleeding is a characteristic of puberty menorrhagia occurring between menarche and 19 years of age. It severely affects the quality of life. There is no statistically significant difference in the prevalence of various menstrual disorders across early middle and late adolescent categories. Medical evidence points out that as of the third year after menarche the interval among bleeding durations is within the range of 21-34 days, with a flow lasting from three to 7 days and an average menstrual blood loss of $35 \mathrm{ml}$ (range $5-80 \mathrm{ml}$ ). The subject reported to have any of the menstrual disorder constitute (polymenorrhea, oligomenorrhea, hypomenorrhea and menorrhagia 550 (82.8\%)while 451 (67.31\%) reported to have premenstrual symptoms. Among those reported, 99 (14.7\%) has had only any one of the symptoms while 451 (67.4\%) were with multiple symptoms.

\subsection{Menstrual Hygiene Practices}

Out of the 670 respondents who have attained menarche, 668 (99.7\%) girls use pads during their menstruation period and only $2(0.3 \%)$ do not use pads. About596(89.2\%) girlsusecommerciallyavailablesanitary pads and 72 (10.7\%) use old clothes. About 534 (79.9\%) girls change their sanitary regularly or cloth pads at least 2-3 times a day while a few respondents change their pads four times a day $87(13.02 \%) .47(7.03 \%)$ change theirs only once. The usage pattern varies significantly between the urban and rural areas. Of 670 respondents, two girls - one each from rural and urban reported not using any sanitary pads. Out of the rest (668) 596 i.e. $89.2 \%$ of the 
Table 4. Menstrual hygiene practices

\begin{tabular}{|l|c|c|}
\hline Region & Usage of pad $\mathbf{n}=\mathbf{6 6 8}$ & $\begin{array}{c}\text { Type of pad use- } \\
\text { commercial-n }=596\end{array}$ \\
\hline Rural & $460(68.9 \%)$ & $396(66.4)$ \\
\hline urban & $208(31.1 \%)$ & $200(33.6 \%)$ \\
\hline total & 668 & 596 \\
\hline & $x 2=331$ & $x 2=14.35$ \\
& $\begin{array}{c}\mathrm{df}=1 \\
\mathrm{p}=0.565\end{array}$ & $\begin{array}{c}\mathrm{p}-<0.0001 \\
\end{array}$ \\
& OR-2.21(.138-35.5) & OR .274(0.134-562) \\
\hline
\end{tabular}

respondents used commercially available sanitary pads regularly. The usage pattern varies significantly between the urban and rural areas. Chi-square $\times 2=14.35$ with df- 1 and $\mathrm{p}$ value $\mathrm{p}-<0.0001$ and Odds Ratio OR .274 (0.134562).

Regarding menstrual hygiene practices surprisingly rural areas reported higher use of sanitary pads. There is significant difference between rural and urban in the usage of commercial pads and this may be due to difference in accessibility to commercial sanitary pads or better menstrual hygiene practices.

\subsection{Disposal of Sanitary Pads}

$516(77.25 \%)$ girls dispose their pads by burning, while $114(17.06 \%)$ flush the used pads in toilets and 8 (1.19\%) respondents throw away the pads in the open area. Method of disposal among 30 (4.49\%) of the respondents is not known.

\section{Conclusion}

Adolescent menstrual disorders are found to be widely prevalent but it is not known how the young women get the information regarding menstruation. The source of information is also not known. The issues of early maturation and menstruation are unresolved.
It is important for clinicians as well as the girls and their parents to understand about normal menstrual patterns. This is important to evaluate the patterns such as irregular cycle or abnormal flow.

Healthcare providers need to focus on these adolescent girls who are going through pubertal transition because they have an opportunity to discuss reproductive health issues with mothers and their daughters, to make an early diagnosis and to choose an appropriate treatment, thus minimizing the negative outcomes caused by these disorders. "Normal versus abnormal" cycles can be charted by using a calendar. An understanding of the menstrual hygiene practices including the disposal of napkins also helps in formulating appropriate strategies and educational packages at the school level itself. This is important from both health and environment angle. In conclusion, it can be stated that an integrated approach involving clinical, educational and behavioral strategies may help in resolving many of the problems identified in this paper

\section{References}

1. Dua T. Coming of age: Adolescent health mental health expert opinion adolescents aiming for healthy future. WHO. 2018.

2. Meier PR, Nickerson HJ, Olson KA, Berg RL, Meyer JA. Prevention of iron deficiency anemia in adolescent and adult pregnancies. Clinical Med Research. 2003 Jan ;1(1):29-36. PMid: 15931282 PMCid: PMC1069018. https://doi.org/10.3121/cmr.1.1.29

3. Paul D, Gopalakrishnan S. Knowledge and practices of adolescent girls regarding reproductive health with special emphasis on hygiene during menstruation, an ICMR funded research project. National Institute of Public Cooperation and Child-development; 2007. p. 1-98.

4. Bieniasz J, Zak T, Laskowska-Zietek A, NoczyńskaA. Causes of menstrual disorders in adolescent girls -

Table 5. Disposal of sanitary pads

\begin{tabular}{|l|c|c|c|c|c|}
\hline $\begin{array}{l}\text { Description } \\
\text { Region }\end{array}$ & Burning & Throwing away & Flushing toilet & Others & total \\
\hline Rural & $344(66.7 \%)$ & $7(87.2 \%)$ & $88(77.2 \%)$ & $21(70 \%)$ & $460(68.8 \%)$ \\
\hline Urban & $172(33.3 \%)$ & $1(12.5 \%)$ & $26(22.8 \%)$ & $9(30 \%)$ & $208(31.2 \%)$ \\
\hline Total & $516(100 \%)$ & $8(100 \%)$ & $114(100 \%)$ & $30(100 \%)$ & $668(100 \%)$ \\
\hline $\mathbf{2}=\mathbf{6 . 1 3}, \mathbf{d f}=\mathbf{3}$, p value $=\mathbf{0 . 1 0 5}$ old value \\
\hline
\end{tabular}


a retrospective study. Middle East Fertility Society Journal. 2006; 11:1-17.

5. Flug D, Largo RH, Prader A. Menstrual patterns in adolescents in Swiss girls: A Longitudinal study. Annals of Human Biology.1984; 11(6):495-508. PMid: 6524865. https://doi. org/10.1080/03014468400007411

6. Raveendran RC, Jacob AM, Ismail J. A delve into the menstrual problems in teenagers: A cross sectional study in an urban school in Kerala. India International Journal of Reproduction, Contraception, Obstetrics and Gynecology. 2016 Nov; 5(11):3978-82. https://doi.org/10.18203/2320-1770.ijrcog20163874

7. Abdella, NHA, Nasr Abd-Elhalim EHN, Attia AMF. The Body Mass Index and menstrual problems among adolescent students: IOSR Journal of Nursing and Health Science. 2016; 5(4): 13-21. https://doi. org/10.9790/1959-0504021321

8. Cakir M, Mungan I, Karakas T, Girisken I, Okten A. Menstrual pattern and common menstrual disorders among university students in Turkey. Pediatr Int. 2007; 49:938-42. PMid: 18045301. https://doi. org/10.1111/j.1442-200X.2007.02489.x

9. Singh A, Kiran D, Singh H, Nel B, Singh P, Tiwari P, et al. Prevalence and severity of dysmenorrhea: A problem related to menstruation, among first and second year female medical students. Indian J Physiol Pharmacol. 2008; 52:389-97.

10. Thomas F, Renaud F, Benefice E, de Meeus T, Guegan JF. International variability of ages at menarche and menopause: Patterns and main determinants. Hum
Biol. 2001; 73:271-90. PMid: 11446429. https://doi. org/10.1353/hub.2001.0029

11. Sinha S, Srivastava JP, Sachan B, Singh RB. A study of menstrual of menstrual pattern and prevelance of Dysmenorrhea during menstruation among school going adolescent girls in Lucknow district, Utter Pradesh, India. International Journal of Community Medicine and Public Health. 2016 May; 3(5):1200-3. https://doi.org/10.18203/2394-6040. ijcmph20161384

12. Sachan B, Idris MZ, Jain S, Kumari R, Singh A. Age at menarche and menstrual problems among school-going adolescent girls of a North Indian district. Journal of Basic and Clinical Reproductive Sciences. 2012; 1(1):56-9. https://doi.org/10.4103/2278960X.104298

13. Bachmann GA, Kemmann E. Prevalence of oligomenorrhea and amenorrhea in a college population. American Journal of Obstetrics and Gynecology. 1982; 144(1):09-102. DOI. 10.1016/0002-9378(82)90402-1

14. Hickey M, Balen A. Menstrual disorders in adolescence: Investigation and management. Hum Reproduction Update. 2003; 9(5):493-504. PMid: 14640381. https://doi.org/10.1093/humupd/dmg038

15. Rigon F, De Sanctis V, Bernasconi S, Bianchin L, Bona G, Bozzola M, Buzi F, Radetti G, Tato L, Tonini G, De Sanctis C, Perissinotto E. Menstrual pattern and menstrual disorders among adolescents: An update of the Italian datasss. 2012; 38:38. PMid: 22892329 PMCid: PMC3462713. doi: 10.1186/18247288-38-38 